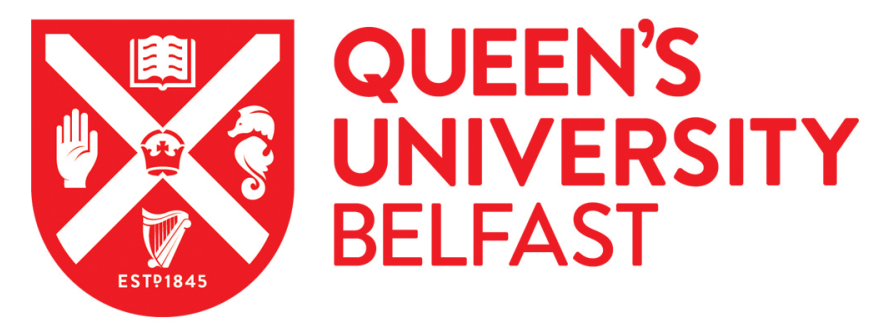

\title{
Hot deformation characteristics of a nitride strengthened martensitic heat resistant steel
}

Zhang, W-F., Li, X-L., Sha, W., Yan, W., Wang, W., Shan, Y., \& Yang, K. (2014). Hot deformation characteristics of a nitride strengthened martensitic heat resistant steel. Materials Science and Engineering A, 590, $199-208$. https://doi.org/10.1016/j.msea.2013.10.020

\section{Published in:}

Materials Science and Engineering $A$

\section{Document Version:}

Peer reviewed version

\section{Queen's University Belfast - Research Portal:}

Link to publication record in Queen's University Belfast Research Portal

\section{Publisher rights}

This is the author's version of a work that was accepted for publication in Materials Science and Engineering: A. Changes resulting from the publishing process, such as peer review, editing, corrections, structural formatting, and other quality control mechanisms may not be reflected in this document. Changes may have been made to this work since it was submitted for publication. A definitive version was subsequently published in Materials Science and Engineering: A, vol 590, January 2014, doi: 10.1016/j.msea.2013.10.020.

\section{General rights}

Copyright for the publications made accessible via the Queen's University Belfast Research Portal is retained by the author(s) and / or other copyright owners and it is a condition of accessing these publications that users recognise and abide by the legal requirements associated with these rights.

Take down policy

The Research Portal is Queen's institutional repository that provides access to Queen's research output. Every effort has been made to ensure that content in the Research Portal does not infringe any person's rights, or applicable UK laws. If you discover content in the Research Portal that you believe breaches copyright or violates any law, please contact openaccess@qub.ac.uk. 


\title{
Hot deformation characteristics of a nitride strengthened martensitic heat resistant steel
}

\author{
Wen-Feng Zhang ${ }^{1,2,3}$, Xiao-Li Li ${ }^{4}$, Wei Sha ${ }^{5}$, Wei Yan ${ }^{1}$, Wei Wang ${ }^{1}$, Yi-Yin Shan ${ }^{1}$, \\ Ke Yang ${ }^{1 *}$ \\ ${ }^{1}$ Institute of Metal Research, Chinese Academy of Sciences, Shenyang 110016, China \\ ${ }^{2}$ University of Science and Technology of China, Hefei 230026, China \\ ${ }^{3}$ Graduate School of Chinese Academy of Sciences, Beijing 100049, China \\ ${ }^{4}$ University of Science and Technology Liaoning, Anshan 114000, China \\ ${ }^{5}$ School of Planning, Architecture \& Civil Engineering, Queen's University Belfast, Belfast \\ BT9 5AG, UK \\ ${ }^{*}$ Corresponding author. Tel.: +86 24 23971628; fax: +86 2423971628 \\ E-mail address: kyang@imr.ac.cn (Ke Yang)
}

\begin{abstract}
Constitutive equations including an Arrhenius term have been applied to analyze the hot deformation behavior of a nitride-strengthened (NS) martensitic heat resistant steel in the temperature range of $900-1200{ }^{\circ} \mathrm{C}$ and in the strain rate range of $10^{-3}-10^{0}$ $\mathrm{s}^{-1}$. On the basis of analysis of the deformation data, the stress-strain curves up to the peak were divided into four regions, in sequence, representing four processes, namely hardening, dynamic recovery (DRV), dynamic strain induced transformation (DSIT), and dynamic recrystallization (DRX), according to the inflection points in $\partial \theta / \partial \sigma$ and $\partial(\partial 0 / \partial \sigma) / \partial \sigma$ curves. Some of the inflection points have their own meanings. For examples, the minimum of $\partial \theta / \partial \sigma$ locates the start of DRV and the maximum of it indicates the start of DRX. The results also showed that the critical strain of DRX was sensitive to $\ln (Z)$ below 40 , while the critical stress of DRX was sensitive to it above 40. The final microstructures under different deformation conditions were analyzed in
\end{abstract}


terms of softening processes including DRV, DRX, metadynamic crystallization (MDRX) and DSIT.

Keywords: steel; mechanical characterization; martensite; thermomechanical processing; recrystallization; phase transformation

\section{Introduction}

The hot deformation of steels has attracted extensive and diverse research activities due to both various phases and different process requirements ${ }^{[1,2]}$. Various softening mechanisms, such as dynamic recovery (DRV), dynamic recrystallization (DRX), metadynamic recrystallization (MDRX) and dynamic strain induced transformation (DSIT) would take place and the grain size could be refined during the deformation in the austenite state of the steels. DRX occurs at a critical strain $\left(\varepsilon_{c}\right)$ where the dislocation density reaches a critical value while DRV, which is the principal mechanism of reducing flow stress $\sigma$ and the strain hardening rate $(\theta=d \sigma / d \varepsilon)$, happens at all levels of strain beyond 0.1 . However, The MDRX usually happens between rolling stands and changes the grains nucleated during DRX. It is also believed that MDRX would also take place under the deformation condition with a small strain rate ${ }^{[3]}$. Finally, DSIT happens when two preconditions, the critical strain for DSIT and the temperature being above $\mathrm{Ar}_{3}$, are met simultaneously.

Which softening processes will occur during deformation depends on the ZenerHollomon $(Z)$ value. This $Z$ value embodies the combined effect of deformation temperature and the strain rate ${ }^{[2]}$. Therefore, the softening process would be determined by calculation of the stress-strain curves up to the peak and explained by the microstructure observation ${ }^{[4]}$. The deformation of nitride strengthened (NS) martensitic heat resistant steel in the austenite phase provides a different opportunity for study of the dislocation substructures and the progress of softening mechanisms mentioned above, and especially how these softening mechanisms are affected by $\mathrm{Z}$ parameter. 
The nitride-strengthened (NS) martensitic heat resistant steel, studied in this work, has been developed to maintain the microstructure stability during creep exposure by precipitate hardening provided by thermally stable nitrides. Up to now, it has primarily succeeded in producing the same initial strength ${ }^{[5]}$ and creep strength level as the commercial P92 steel at $600{ }^{\circ} \mathrm{C}, 180 \mathrm{MPa}$, which can be related to the hardening contribution of nano-sized MX type nitrides and their high thermal stability.

This paper will precisely determine the accurate strains where different softening processes take place, after establishing the constitutive equation for the NS martensitic steel by calculating the activate energy $\mathrm{Q}$, the $\mathrm{Z}$ parameter, and the stress sensitivity coefficient $\mathrm{n}$. Subsequently, the predominate softening processes under different deformation conditions could be identified and the corresponding microstructure evolution could be understood.

\section{Experimental}

The chemical composition of the experimental NS steel is given in Table 1. The steel was melted in a vacuum induction-melting furnace and then forged into a slab with a transversal surface of $60 \times 90 \mathrm{~mm}^{2}$ at $900-1150^{\circ} \mathrm{C}$. Bars for compression test cut from the slab perpendicular to the forging direction were machined into samples with diameters of $8 \mathrm{~mm}$ and gauge length of $12 \mathrm{~mm}$.

In order to study the deformation characteristics of the experimental steel, compression tests at different strain rates were carried out. All the samples were homogenized in vacuum at $1200{ }^{\circ} \mathrm{C}$ for $5 \mathrm{~min}$, and then cooled down to the deformation temperature of $900-1200{ }^{\circ} \mathrm{C}$ at the rate of $10{ }^{\circ} \mathrm{C} / \mathrm{s}$. After isothermal stabilizing for $1 \mathrm{~min}$ at the deformation temperature, the samples were deformed up to $60 \%$ in a strain rate range of $10^{-3}-10^{0} \mathrm{~s}^{-1}$. The samples were quenched to room 
temperature as soon as the compression was finished. The procedure is illustrated in Figure 1.

The continuous stress-strain curves under all deformation conditions were obtained to define the full dynamic recrystallization behavior and calculate the constitutive parameters.

Table 1 Chemical composition of the experimental NS steel, wt.\%

\begin{tabular}{ccccccccccc}
\hline $\mathrm{C}$ & $\mathrm{Si}$ & $\mathrm{Mn}$ & $\mathrm{Cr}$ & $\mathrm{W}$ & $\mathrm{V}$ & $\mathrm{Nb}$ & $\mathrm{N}$ & $\mathrm{S}$ & $\mathrm{P}$ & $\mathrm{O}$ \\
\hline 0.021 & 0.09 & 1.25 & 9.37 & 1.42 & 0.15 & 0.06 & 0.037 & 0.002 & 0.004 & 0.0082 \\
\hline
\end{tabular}

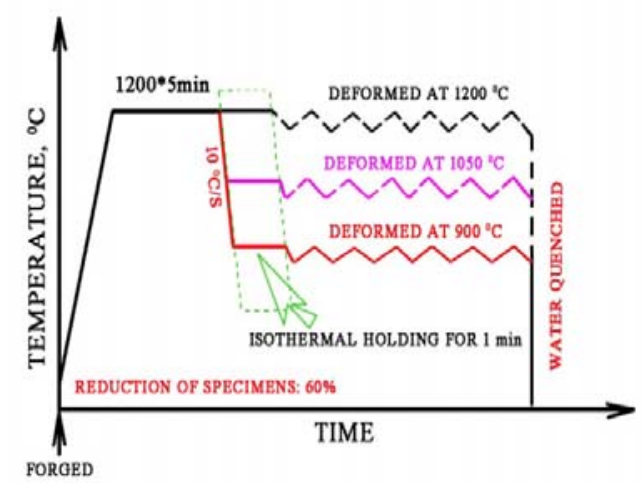

Figure 1. The deformation procedure for the experimental NS steel.

\section{Results}

\subsection{True stress-strain curves}

Figure 2 gives the true stress-strain curves of specimens for four different strain rates which are labeled beside their corresponding curves, as well as the critical strain, $\varepsilon_{\mathrm{c}}$ and the peak strain, $\varepsilon_{\mathrm{p}}$.

All the stress curves show an initial work hardening but only some develop to a clear peak indicating the DRX taking place. Some of the curves under low $\mathrm{Z}$ value, such as $1200{ }^{\circ} \mathrm{C} / 10^{-3}-10^{-2} \mathrm{~s}^{-1}$, even exhibit multiple peaks. The peaks likely occur under high temperature low strain rate (low $\mathrm{Z}$ values) conditions. With the increase of $\mathrm{Z}$ value, 
the peak becomes broad and even disappears if the $\mathrm{Z}$ value is high enough, such as the stress-strain curves obtained at $900{ }^{\circ} \mathrm{C}$, which show a 'flat-top' shape with no distinct peak. This flat-top shape is traditionally assumed to be an indication of no DRX occurring, implying that the DRV is the only softening mechanism to operate during the deformation process ${ }^{[3]}$.
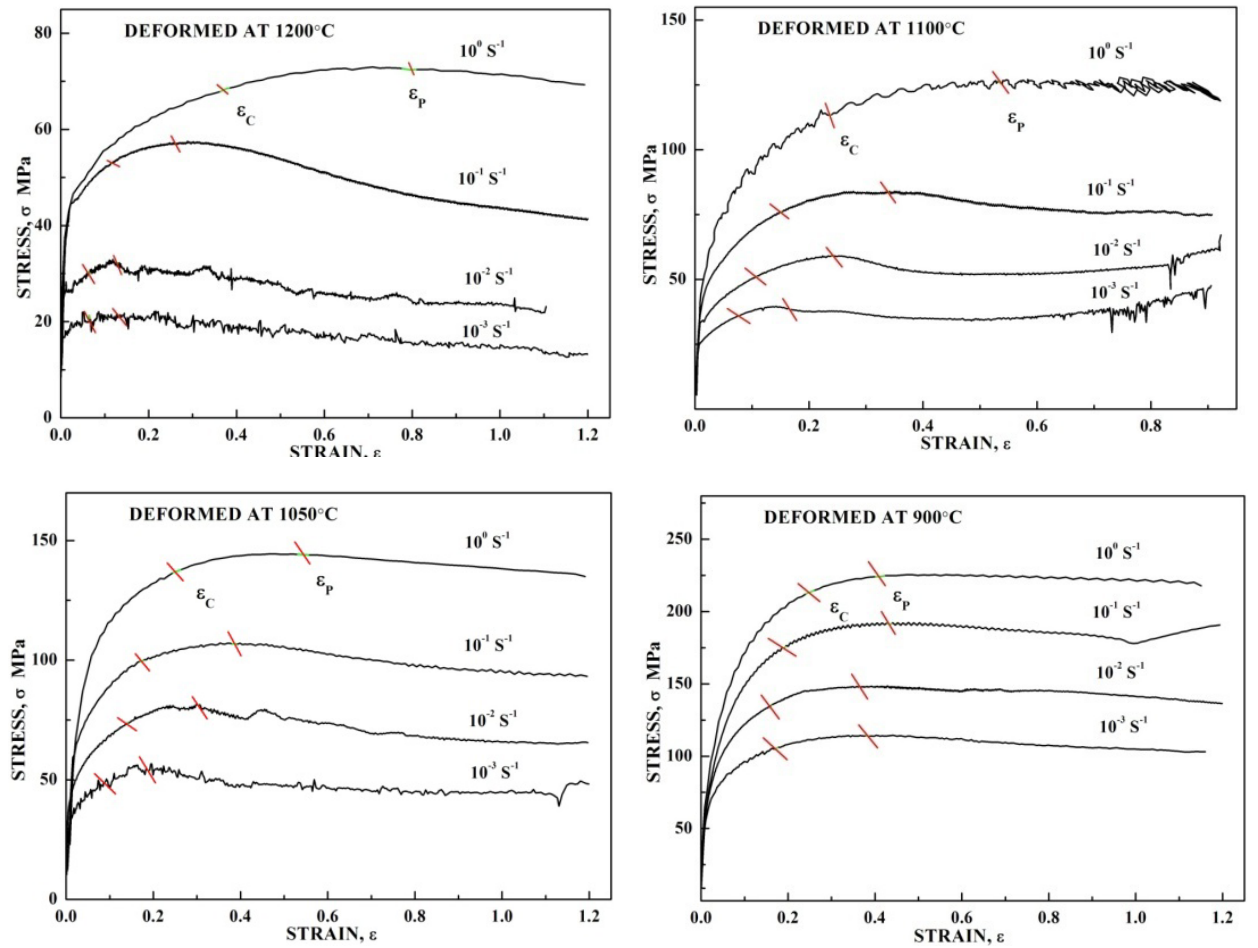

Figure 2. True stress-strain curves with indication of $\varepsilon_{\mathrm{c}}$ and $\varepsilon_{\mathrm{p}}$ for NS steel samples deformed at 900$1200{ }^{\circ} \mathrm{C}$.

Generally speaking, at a certain deformation temperature, the flow stress increases with the strain rate rising. However, when considering the flow curves of the NS steel, it was found that an increase in strain rate had less effect on the increase in the flow stress, at the lower temperatures. The stress augmentation ratio $\left(\mathrm{r}=\left(\sigma_{2}-\sigma_{1}\right) / \sigma_{1}\right)$ calculated, in terms of the peak stress, ranged between 0.30 to 2.56 at temperature of $1200{ }^{\circ} \mathrm{C}$ and ranged between 0.17 to 0.97 at $900{ }^{\circ} \mathrm{C}$. Therefore, as the temperature was decreased from $1200{ }^{\circ} \mathrm{C}$ to $900{ }^{\circ} \mathrm{C}$, the stress augmentation ratio with strain rate rising diminished. This diminishing influence of strain rate on flow stress as temperature is decreased is a reflection of the effective strain rate sensitivity 
$(m=\partial \log \sigma(\partial \log \varepsilon))$ of the material. The $m$ value decreasing with temperature declining and strain rate increasing was expected to be associated with the low stacking fault energy $(\mathrm{SFE})^{[4]}$.

\subsection{Constitutive equations}

The stress-strain curves up to the peaks were calculated in the reduced formula as expressed in Eq. $1^{[4]}$. The value of $\sigma$ is a function of $\varepsilon$ as well as of T and $\dot{\varepsilon}$.

$$
\sigma / \sigma_{\mathrm{p}}=\left[\left(\varepsilon / \varepsilon_{\mathrm{p}}\right) \exp \left(1-\varepsilon / \varepsilon_{\mathrm{p}}\right)\right]^{\mathrm{C}}
$$

where the exponent $\mathrm{C}$ was derived for different steels. The peak strain $\varepsilon_{\mathrm{p}}$ corresponds to the peak stress $\sigma_{\mathrm{p}}$ employed in the constitutive equations.

Generally, the power function $\left(\varepsilon=A^{\prime} \sigma^{\mathrm{n}}\right)$ can only be successfully used in cold working with continuous hardening while the exponential function $\left(A^{\prime \prime} \exp (\beta \sigma)=\operatorname{cexp}(\mathrm{Q} / \mathrm{RT})\right)$ is applicable to predict a peak saturation stress in a low stress curve. However, the constitutive equation (Eq. 2) could be used in both high stress and low stress ${ }^{[6]}$ :

$$
\mathrm{Z}=\varepsilon \exp (\mathrm{Q} / \mathrm{RT})=\mathrm{A}[\mathrm{s} \operatorname{lnh}(\alpha \sigma)]^{\mathrm{n}}
$$

where the coefficients are the stress exponent $n$, the activation energy $Q$, the parameter $\alpha$ which is constant for a fixed alloy and the gas constant $\mathrm{R}$ is $8.314 \mathrm{~J} \mathrm{~mol}^{-1}$ $\mathrm{K}^{-1}$. The $\alpha$ value was firstly fixed to 0.011 , through a method mentioned by Zhang et al. ${ }^{[7]}$.

Take natural logarithm of Eq. 2:

$$
\ln \dot{\varepsilon}+\frac{\mathrm{Q}}{\mathrm{RT}}=\ln \mathrm{A}+\mathrm{n} \ln [\sinh (\alpha \sigma)]
$$

Re-arranging: 


$$
\ln \dot{\varepsilon}=\mathrm{n} \ln [\sinh (\alpha \sigma)]+\ln \mathrm{A}-\frac{\mathrm{Q}}{\mathrm{RT}}
$$

By plotting $\ln \dot{\varepsilon}$ against $\ln [\sinh (\alpha \sigma)]$, at constant temperatures, we can obtain $\mathrm{n}$ from the slope of the linear regression lines, Figure 3(a). The value of $\mathrm{n}$ averaged from the slopes of the four regression lines shown in the figure, for the four temperatures of tests, is $5.00 \pm 0.23$, for the NS steel. This agrees with the $\mathrm{n}$ value previously fixed to 5.21 , through a method mentioned by Zhang et al. ${ }^{[7]}$.

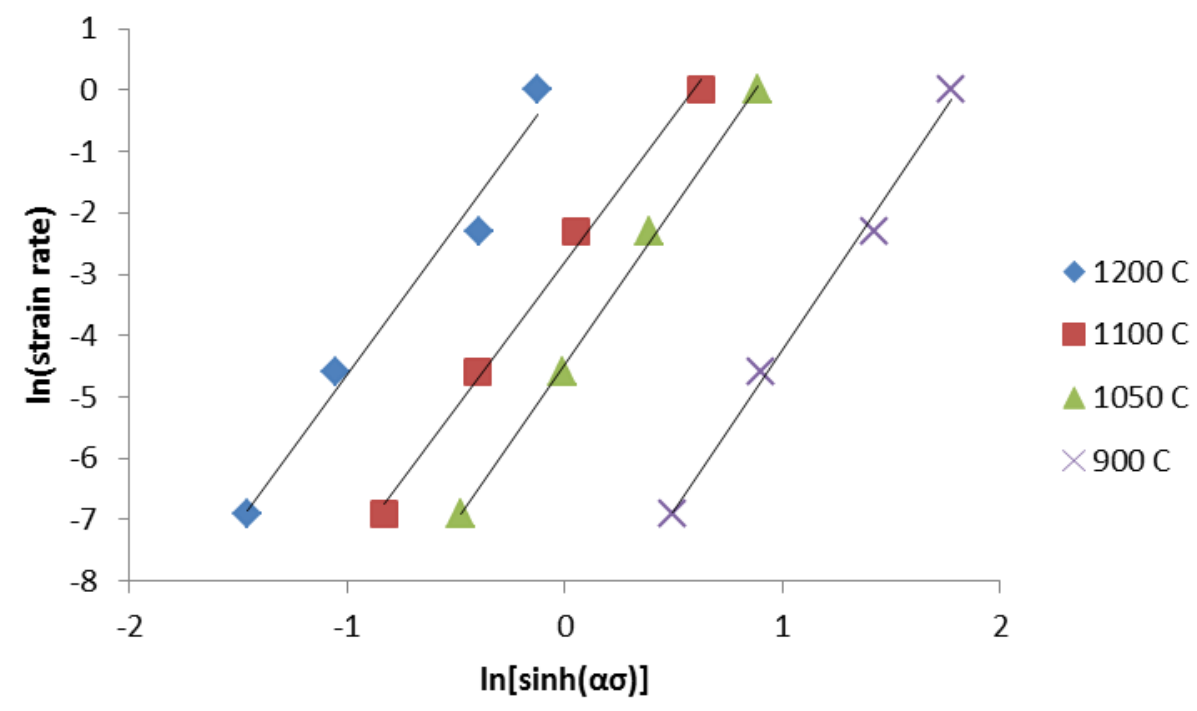

(a)

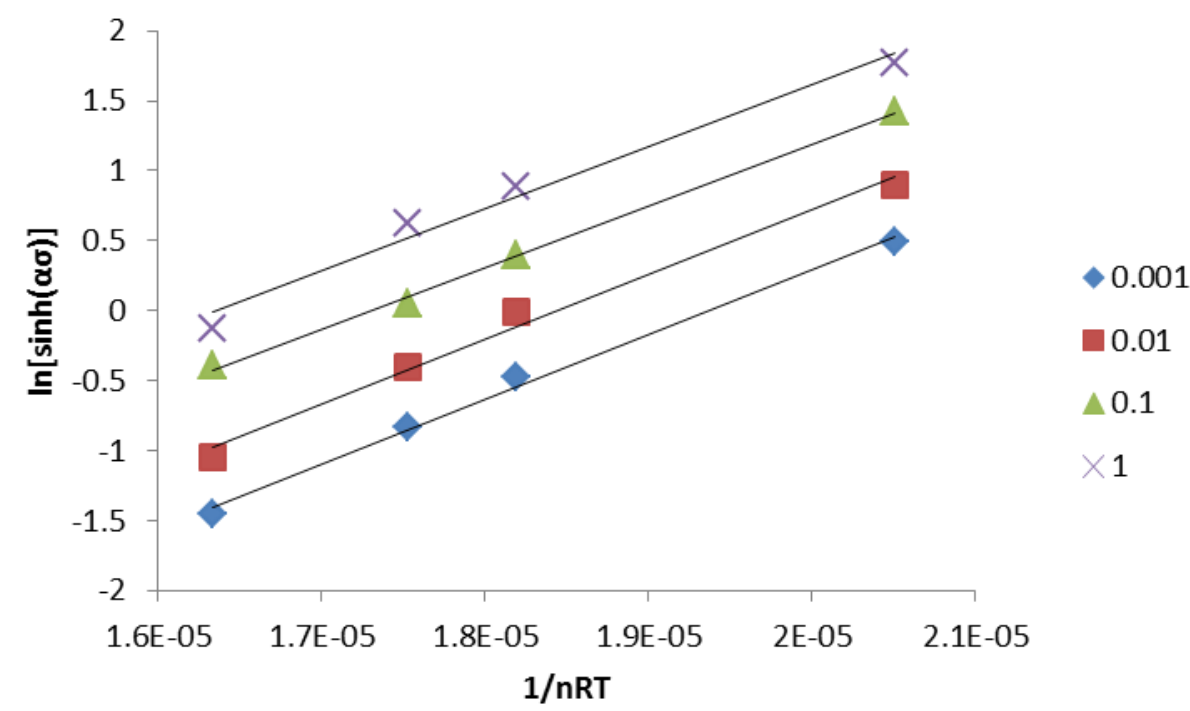

(b)

Figure 3. Linear relationships of (a) $\ln \notin$ versus $\ln [\sinh (\alpha \sigma)]$ and $(b) \ln [\sinh (\alpha \sigma)]$ versus $\frac{1}{\mathrm{nRT}}$. 
Re-arranging Eq. 3 differently:

$$
\ln [\sinh (\alpha \sigma)]=\frac{\mathrm{Q}}{\mathrm{nRT}}+\frac{\ln \dot{\varepsilon}-\ln \mathrm{A}}{\mathrm{n}}
$$

By plotting $\ln [\sinh (\alpha \sigma)]$ against $\frac{1}{\mathrm{nRT}}$, at constant strain rates, we can obtain the activation energy Q from the slope of the linear regression lines, Figure 3(b). The value of activation energy Q of the NS steel at the peak strain averaged from the slopes of the four regression lines shown in the figure, for the four strain rates of tests, is $451 \pm 13 \mathrm{~kJ} / \mathrm{mol}$.

Finally, substituting the above $\mathrm{n}$ and $\mathrm{Q}$ values into Eq. 2, the average A value is obtained, $(1.1 \pm 0.4) \times 10^{16}$. The apparently large error in $\mathrm{A}$ is because, in Eq. 2, $\mathrm{A}$ is linear but the terms containing $\mathrm{Q}$ and $\sigma$ are exponential, as well as power $\mathrm{n}$ for the latter. So, small errors in $\mathrm{Q}, \sigma$ and $\mathrm{n}$ will generate a large error in $\mathrm{A}$.

\subsection{The critical condition for DRX}

It has been reported that the absence of stress peaks in flow curves does not necessarily indicate the absence of DRX ${ }^{[6]}$. As for the 'flap-top' stress curves of the NS steel deformed under high $\mathrm{Z}$ condition, DRX was proved to take place through both the strain hardening rate curves depicted in Figure 4 and the microstructure observation in Section 3.5.

The existing approach to locate the onset of DRX is based mainly on energy considerations. Wray ${ }^{[8]}$ was the first to emphasize that the critical strain corresponds to the initiation of DRX. The critical strain for the initiation of DRX can be deduced either from direct microstructure observations or analysis of the flow curve. The former is a more complicated and time consuming process due to the heavy experimental work and the difficulty in determination of the nature of some new grains. 
McQueen et al. ${ }^{[4]}$ suggested that, based on the flow curve analysis, the deviation point of the linear relationship between $\theta(=\mathrm{d} \sigma / \mathrm{d} \varepsilon)$ and $\sigma$ should be defined as the critical strain position. This method gives a visual overview of the approximate location where the DRX starts. The extrapolation of the lower linear $\theta-\sigma$ segment to $\theta=0$ provides the value of a saturation stress $\sigma_{\mathrm{c}}^{*}$ which represents an approximation of the flow stress that would be obtained if only DRV occurs. However, in the case of the NS steel, the extrapolated $\sigma_{\mathrm{c}}^{*}$ value provided an evidence for the occurrence of the softening mechanisms which could involve DRX and DSIT ${ }^{[4]}$. Correspondingly, the change in $\theta$ curve only provides information of $\sigma$ and $\varepsilon$ for subgrain formation and for nucleation of DRX with an approximate value. The slope of the $\theta-\sigma$ curve, which descended from a high value more steeply as T rose and $\dot{\varepsilon}$ declined as shown in Figure 4, changed inconspicuously under some high $\mathrm{Z}$ conditions. Thus, it is difficult to accurately designate the critical strain for both DRV and DRX.

However, Poliakt and Jonas ${ }^{[9]}$ located the precise critical strain for the initiation of DRX by the minimum position of the $-(\partial \theta / \partial \sigma)$. They claimed that the critical amount of stored energy and the minimum of energy dissipation rate together are the sufficient conditions for the initiation of DRX. The $(2 \theta / 2 \sigma)$ curves, depicted in Figure 5, are drawn to statistically analyze the maximum value corresponding to the critical strains of the NS steel. The $(\partial \theta / \partial \sigma)$ value decreases to a minimum and then climbs up to a maximum value with a longer flat-top shape at higher $Z$ values. The 'flat-top' shape denotes that the DRX only depends on the strain and is not sensitive to stress, which will be discussed in a later section. Both methods are employed in the NS steel study as they not only have their own advantages but also can complement each other. The DRX and DRV lines can be drawn on the strain hardening rate curves, as indicated in Figure 4. 


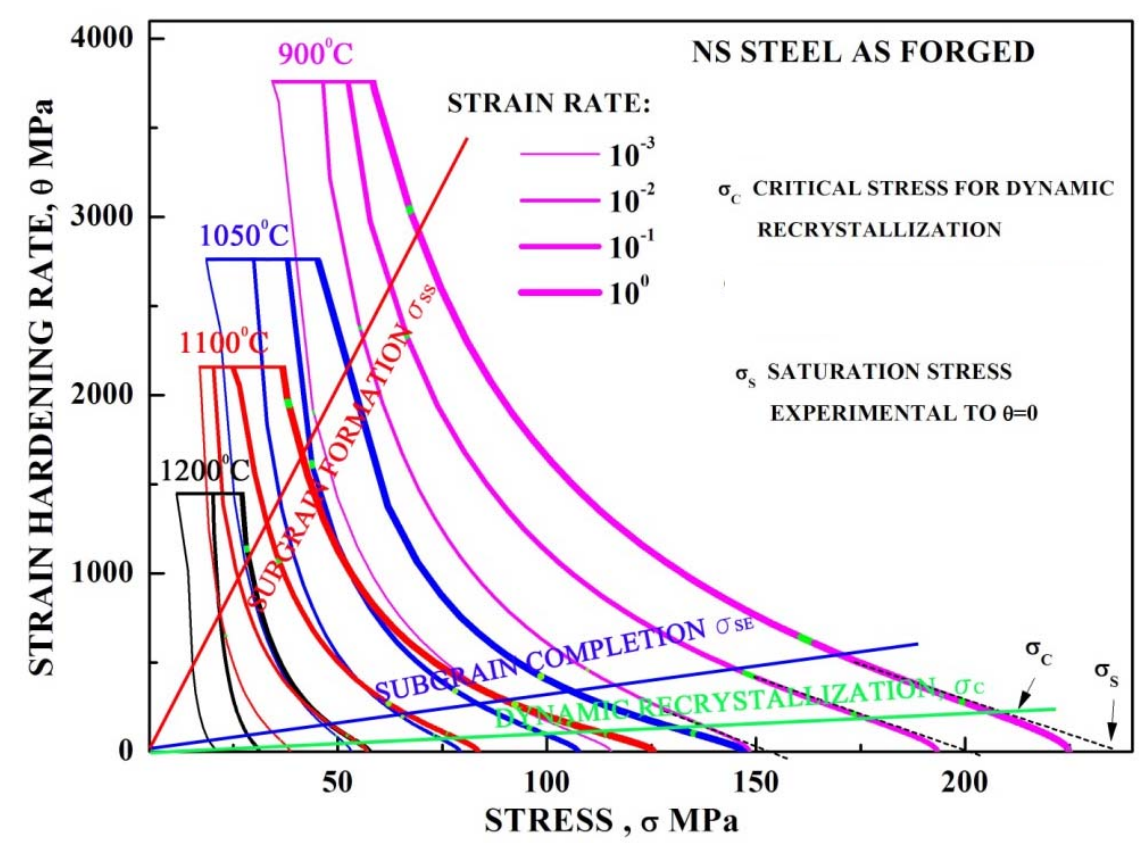

Figure 4. Curves of strain hardening rate $\theta$ versus flow stress up to the peak.

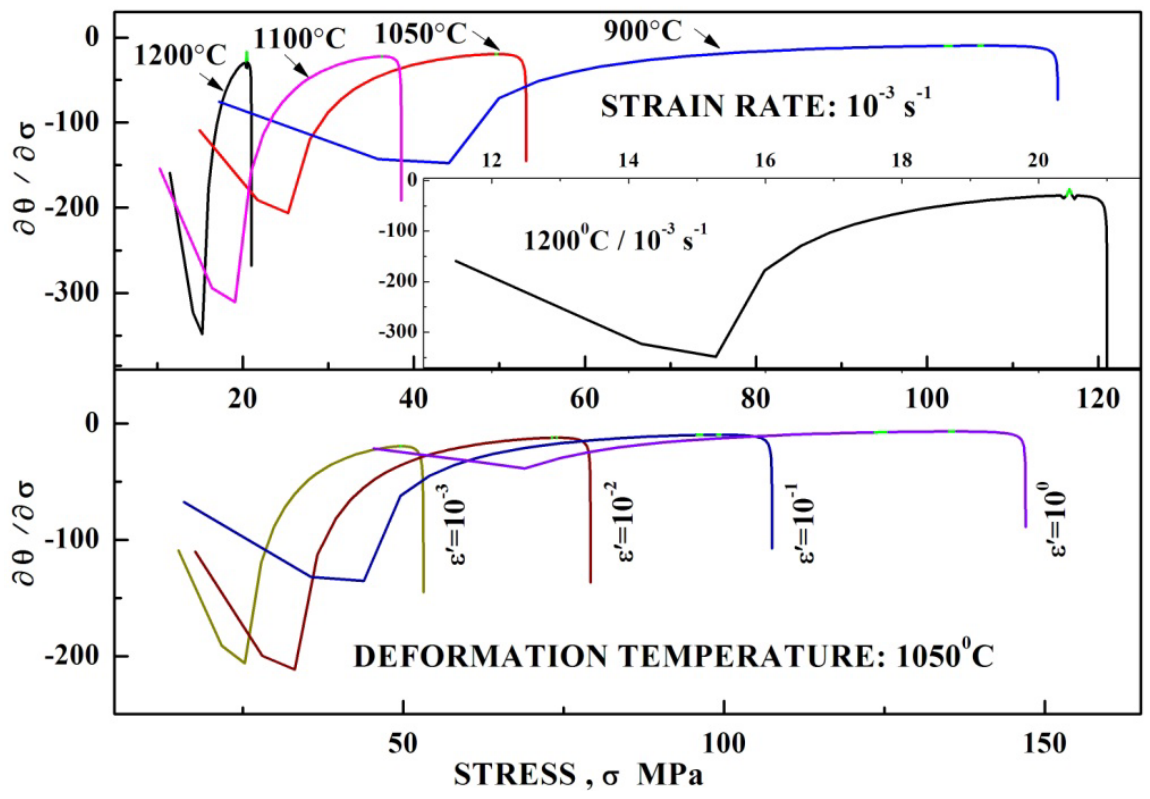

Figure 5. $(2 \theta / \sigma \sigma)$ curves versus flow stress up to the peak.

\subsection{Zener-Hollomon parameter}

In a common understanding, the increase of $\mathrm{Z}$ leads to an increase in $\varepsilon_{c}$, since only small strain is needed to initiate the DRX at low $\mathrm{Z}$ value and with the $\mathrm{Z}$ increase, the critical strain needs to be increased correspondingly. However, other researchers also 
mentioned that high $\mathrm{Z}$ condition may also accelerate the initiation of DRX. They stated that the increase of $\mathrm{Z}$ could lead to a higher dislocation density which would prompt the initiation of $\mathrm{DRX}^{[10]}$ by changing the relative amounts of work hardening and recovery. In the case of the NS steel, the former theory is applicable in the initial part of $\ln (Z)-\ln \left(\varepsilon_{\mathrm{c}}\right)$ curve (Figure 6), and the latter theory well explains the flat trend of $\ln \left(\varepsilon_{\varepsilon}\right)$ when $\ln (Z)$ value is beyond 40 .

At the beginning, $\ln \left(\varepsilon_{c}\right)$ increases linearly with $\ln (Z)$ rising, which has been massively reported by other authors ${ }^{[3,6]}$. However, this increase slows down and levels off at high $\ln (Z)$ value around 40 . The leveling off of $\ln \left(\varepsilon_{\mathrm{c}}\right)$ value has been recorded by Stewart et al. ${ }^{[11]}$, and was explained by the segregation of substitutional impurities ( $\mathrm{P}$ in particular) to the sub-boundaries of newly nucleated DRX grains. This segregation was temperature and, consequently, $\mathrm{Z}$ sensitive. A similar phenomenon was also observed by McQueen et al. ${ }^{[4]}$ during the torsion testing of 316 and 317 stainless steels.

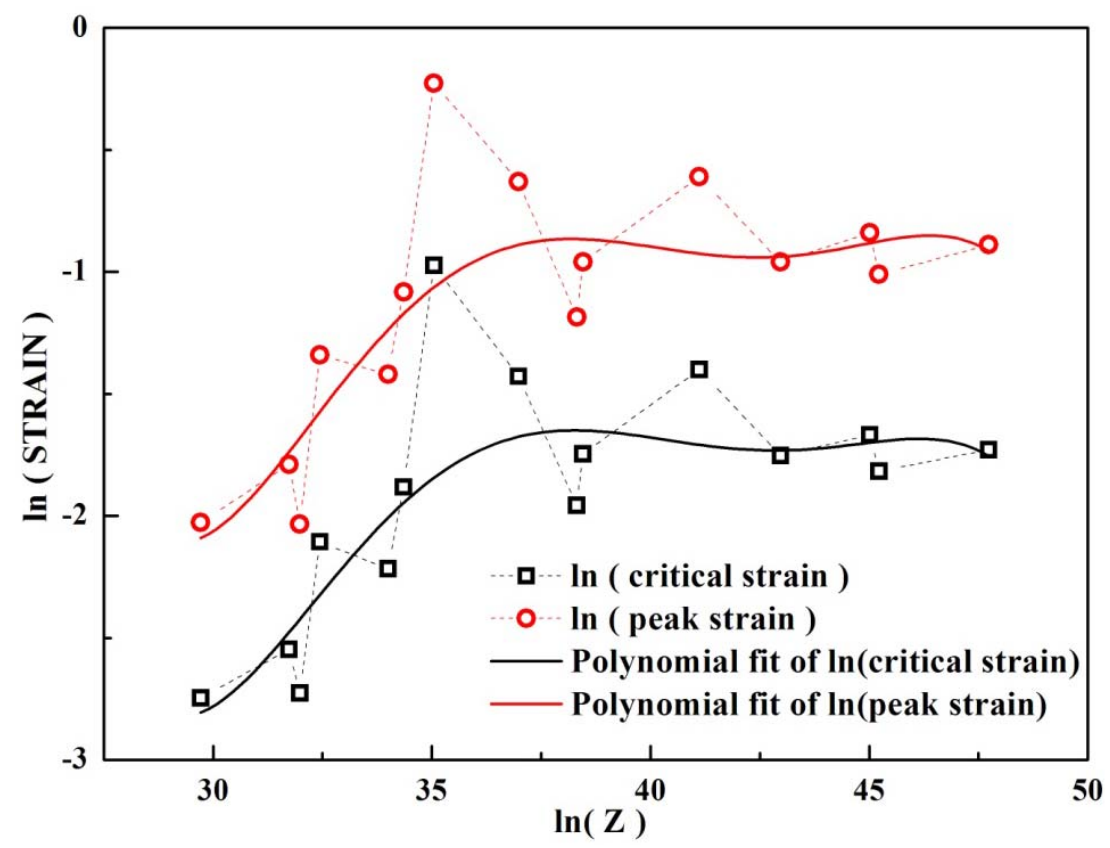

Figure 6. Curves of $\ln \left(\varepsilon_{c}\right)$ and $\ln \left(\varepsilon_{p}\right)$ values versus $\ln (Z)$ value. 
However, as demonstrated in Figure 7 , unlike $\ln \left(\varepsilon_{\mathrm{c}}\right)$, the $\ln \left(\sigma_{\mathrm{c}}\right)$ value shows a continuously increasing trend but with a smaller rate after the initial linear growth. The decrease of growth rate, which might be associated with the effect of the dislocation density on DRX initiation, takes place at the $\ln (Z)$ value around 40 . When the $\ln (Z)$ value reaches a certain level, as 40 for the NS steel, the dislocation density becomes high enough to stimulate the start of DRX, which lowers the critical strain for DRX. In other words, DRX is easier to happen under such condition with a high dislocation density. When the value of $\ln (Z)$ is below 40 , the critical strain for DRX is sensitive to $Z$ value while the critical stress is still sensitive to it when $\ln (Z)$ is beyond 40.

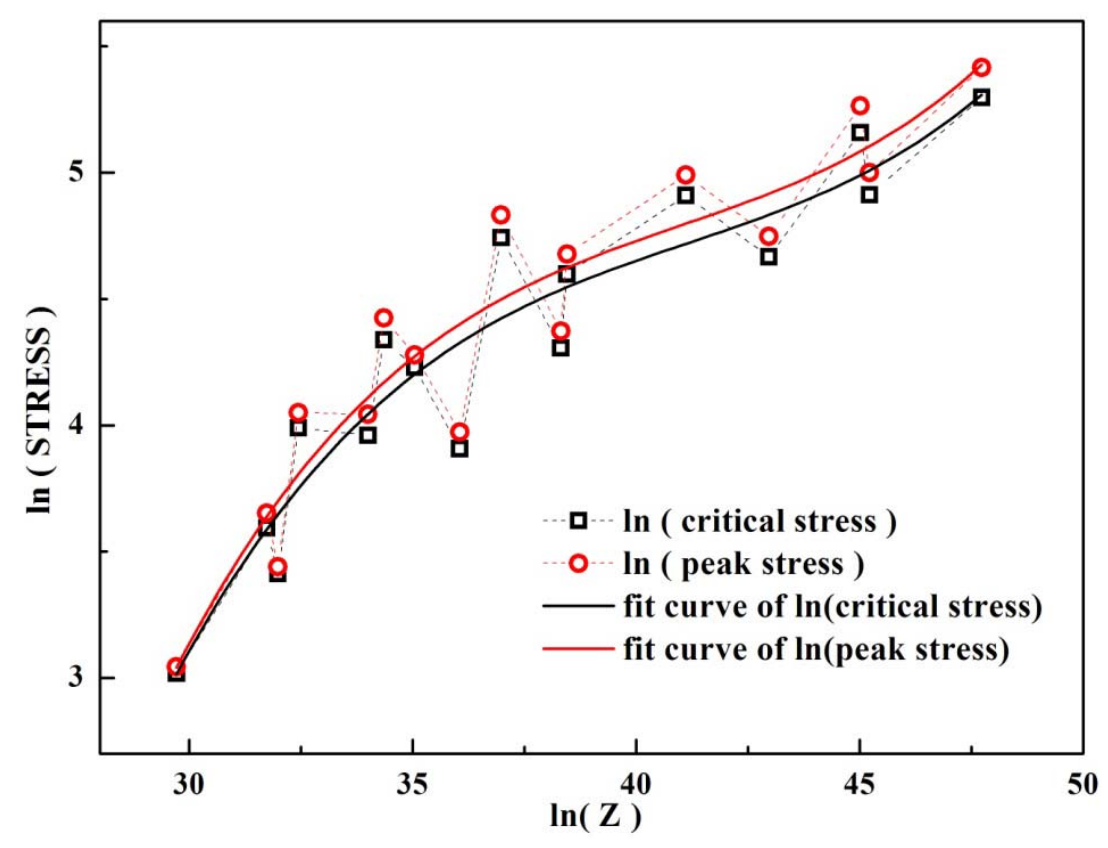

Figure 7. Curves of $\ln \left(\sigma_{c}\right)$ and $\ln \left(\sigma_{p}\right)$ values versus $\ln (Z)$ value.

Although the critical strain for DRX does not increase linearly with $\mathrm{Z}$ value as $\mathrm{Z}$ rises, it keeps a good linear relationship with the peak strain carrying a ratio of 0.45 , illustrated in Figure 8 . The ratio is smaller than those reported by other authors ${ }^{[1,3]}$, which lie in the range of $0.61-0.77$. This diminishing in ratio may be attributed to the DSIT softening occurring before DRX, since the DSIT significantly could reduce the 
stored energy and consequently postpones the subsequent nucleation of DRX after the first nucleation wave. The delay of the subsequent DRX nucleation in turn leads to a larger peak strain, which causes the diminishing of ratio.

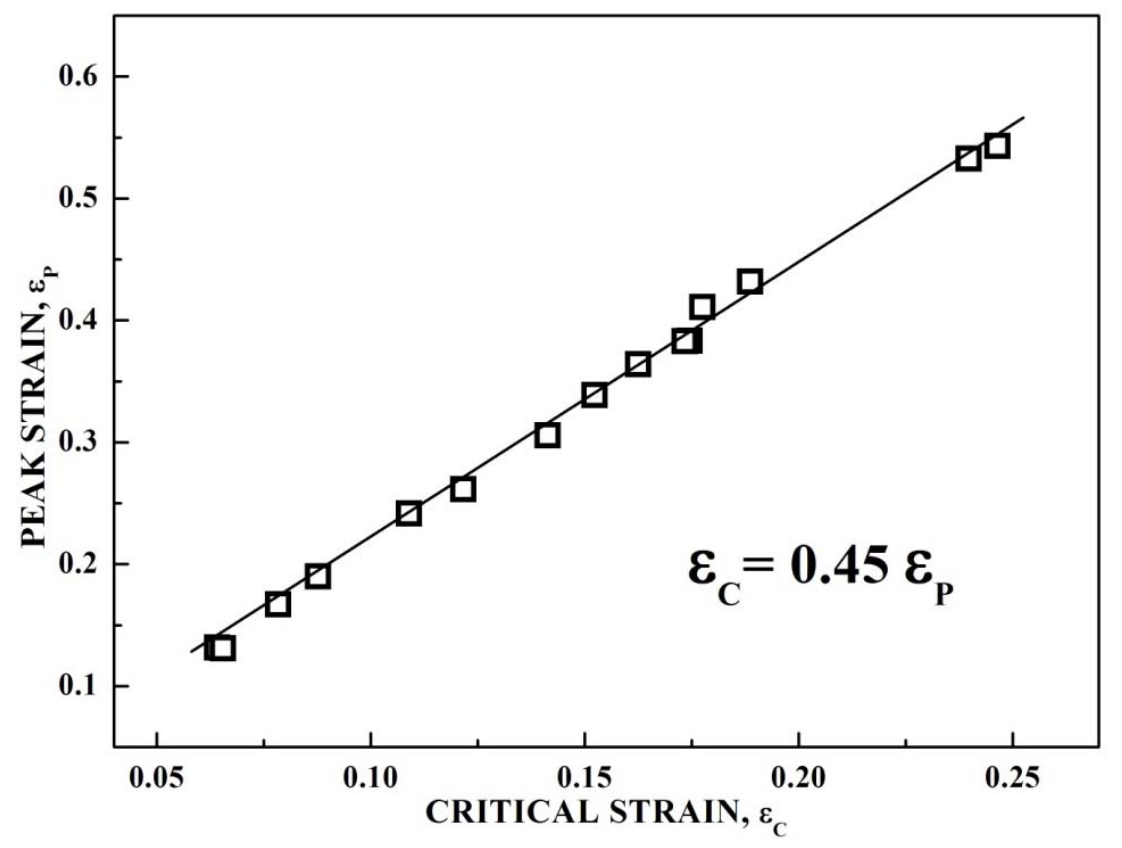

Figure 8. Linear relationship between $\varepsilon_{\mathrm{c}}$ and $\varepsilon_{\mathrm{p}}$ values.

\subsection{Microstructure evolution during hot deformation}

The microstructure evolution of the NS steel during hot deformation is closely related to DRV, DRX, MDRX, and DSIT softening mechanisms. Different softening mechanisms taking in charge resulted in different microstructure characteristics of the NS steel deformed under different deformation condition, as demonstrated in Figure 9.

Under low $\mathrm{Z}$ deformation condition (high temperature and low strain rate), such as $1200{ }^{\circ} \mathrm{C} / 10^{-3} \mathrm{~s}^{-1}$, the microstructure showed no elongated grains but uniform, small, and approximately equiaxed grains. This was a definite proof of DRX to have taken place. However, almost $40 \%$ of the grain volume was ferrite, which indicates that the DSIT also played an important role in the softening. 
The DSIT process gradually took over the main role of the softening as the $\mathrm{Z}$ condition was changed to $1050{ }^{\circ} \mathrm{C} / 10^{-1} \mathrm{~s}^{-1}$. The DSIT ferrite exhibited an elongated shape which indicated no occurrence of DRX in DSIT ferrite while the coexisting martensite indicated that DRX happened in the austenite during deformation. This striped double-phase microstructure was vividly pictured in Figure 9(b).

As the $\mathrm{Z}$ value continuously rose further up to the $900{ }^{\circ} \mathrm{C} / 10^{0} \mathrm{~s}^{-1}$ condition, there was rarely distinct DSIT ferrite left, replaced by a certain volume fraction of ferritemartensite blends. The ferrite-martensite blend microstructure, like the ferrite microstructure, did not clearly show the evidence of DRX taking place while the martensitic microstructure showed fine grains by comparison.

\section{(figure in separate file)}

Figure 9. Microstructure evolution during hot deformation: (a) DRX and DSIT at $1200^{\circ} \mathrm{C} / 10^{-3} \mathrm{~s}^{-1}$, (b)

$$
\text { DRV and DSIT at } 1050{ }^{\circ} \mathrm{C} / 10^{-1} \mathrm{~s}^{-1} \text {, (c) DRV and DRX at } 900^{\circ} \mathrm{C} / 10^{0} \mathrm{~s}^{-1} \text {. }
$$

\section{Discussion}

\subsection{Flow curves}

There are two processes, energy storing and energy dissipating, taking place simultaneously during the hot deformation. The energy dissipated during deformation is usually assumed to be approximately equal to the amount of heat release. However, these quantities are not exactly equal. The difference is small but it plays an essential role in the plastic deformation ${ }^{[12]}$. From a microscopic point of view, two concurrent processes are responsible for the formation of substructure during the deformation. The first is related to the creation and accumulation of dislocations, which can be quantified in terms of the stored energy. The second process is related to the various relaxation processes involved in the motion, rearrangement and annihilation of lattice 
defects $^{[13]}$. The two processes interact with each other in the manner of that an increase in the rate of annihilation results in a decrease of the stored energy and vice versa.

In the analysis of the NS steel, both the $\partial \theta / \partial \sigma$ and the $\partial(\partial \theta / \partial \sigma) / \partial \sigma$ curves are used to explain the process. Since the negative of the $\partial \theta / \partial \sigma$ value was defined as the rate of energy dissipating ${ }^{[9]}$ (softening process), then the $\partial \theta / \partial \sigma$ value would be inferred to stand for the rate of energy changing. Therefore, mathematically and physically, the $\partial(\partial \theta / \partial \sigma) / \partial \sigma$ value could be interpreted as the acceleration of the energy varying. The acceleration could in turn reflect the combined internal stress. Correspondingly, the steel is declared to experience hardening if the acceleration value is positive, softening if negative and balanced if zero. According to the result shown in Figure 10, more slip systems are activated at low $\mathrm{Z}$ value than at high $\mathrm{Z}$ value in the NS steel. Therefore, the maximum value of $\partial(\partial \theta / \partial \sigma) / \partial \sigma$ suggesting hardening stress decreases as the $\mathrm{Z}$ value increases.

To explicitly analyze the processes of softening, the stress-strain curve up to the peak is divided into four regions by the characteristic points in $\partial \theta / \partial \sigma$ and $\partial(\partial \theta / \partial \sigma) / \partial \sigma$ curves. As representative examples, stress curves obtained at $1200{ }^{\circ} \mathrm{C} / 10^{-2} \mathrm{~s}^{-1}$ and $1050{ }^{\circ} \mathrm{C} / 10^{-2} \mathrm{~s}^{-1}$ and their $\theta, \partial \theta / \partial \sigma$ and $\partial(\partial \theta / \partial \sigma) / \partial \sigma$ curves given in Figure 11 are analyzed, region by region. Region I is from the beginning to the minimum of $\partial \theta / \partial \sigma$. In this region, the NS steel experiences only hardening process and no softening processes take place. The $\partial \theta / \partial \sigma$ curve in this region shows a deeper rock bottom and decreases more rapidly at a lower $\mathrm{Z}$ value as the stress rises, which means that the rate of energy dissipating increases rapidly to its peak, indicating that a reversal progress is to take place. 
The minimum of $\partial \theta / \partial \sigma$, where the subgrains are presumed to start and the stored energy begins to dissipate recklessly, is the start boundary of the region II. No other softening mechanism is added in until the maximum value of $\partial(\partial \theta / \partial \sigma) / \partial \sigma$, which is the end boundary of the region II. As for the NS steel, the initial softening mechanism happening at the minimum of $\partial \theta / \partial \sigma$ is DRV. As is clearly shown in the $\partial(\partial \theta / \partial \sigma) / \partial \sigma$ curve in region II, the hardening force characterized in the $\partial(\partial \theta / \partial \sigma) / \partial \sigma$ curve still keeps increasing but with a reduced rate.

Region III is started at the end of the region II and is terminated at the maximum value of $\partial \theta / \partial \sigma$ which is assumed to be related to the critical strain for DRX. This region is the most important part in softening as it determines whether or not the DRX happens. If the stored energy in terms of accumulated and nucleated dislocation reaches the critical amount and the rate of energy dissipation takes the minimum value at the same time, the DRX occurs. If either of the conditions is not met, no DRX takes place. In the beginning of this region, the $\partial(\partial \theta / \partial \sigma) / \partial \sigma$ curve drops dramatically from its summit, which indicates that an auxiliary softening mechanism besides DRV occurs. In the case of the NS steel, the assisting softening is likely DSIT. Within the region III, it also gives a hint on where the subgrains finish, if they do, is given by the onset of the linear part of $\theta-\sigma$ curve or the start point of the $\partial(\partial \theta / \partial \sigma) / \partial \sigma$ values that are barely changed around zero, as indicated in Figure 11. The $\partial(\partial \theta / \partial \sigma) / \partial \sigma$ curve also exhibits a more elongated flat-bottom shape for the higher $\mathrm{Z}$ value than the lower $\mathrm{Z}$ value, as demonstrated in Figure 10. Since the force value of zero is defined to symbolize the balance of hardening and softening forces, the longer the 'flat-bottom' shape gets, the 'sooner' the force balance is received in the flow stress scale. This phenomenon, on a different aspect, explains that the critical 
condition for DRX only depends on the critical strain and not the stress, no matter how 'soon' the value of $\partial(\partial \theta / \partial \sigma) / \partial \sigma$ reaches zero.

Region IV is defined as the critical strain where DRX actually happens. Therefore, the DRX is the main softening mechanism over DRV and DSIT, which is discussed in the following section.

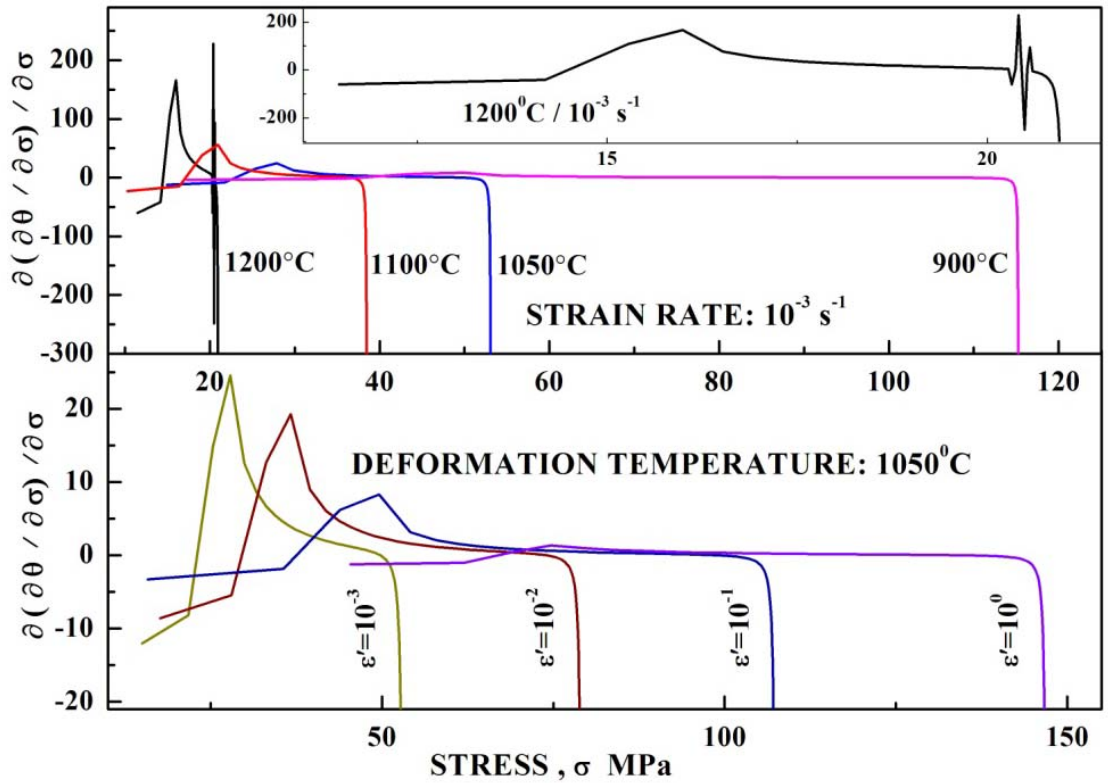

Figure 10. $\partial(\partial \theta / \partial \mathrm{c}) / \partial \sigma$ value versus flow stress over temperature range of $900-1200{ }^{\circ} \mathrm{C}$ and strain rate range of $10^{-3}-10^{0} \mathrm{~s}^{-1}$. 


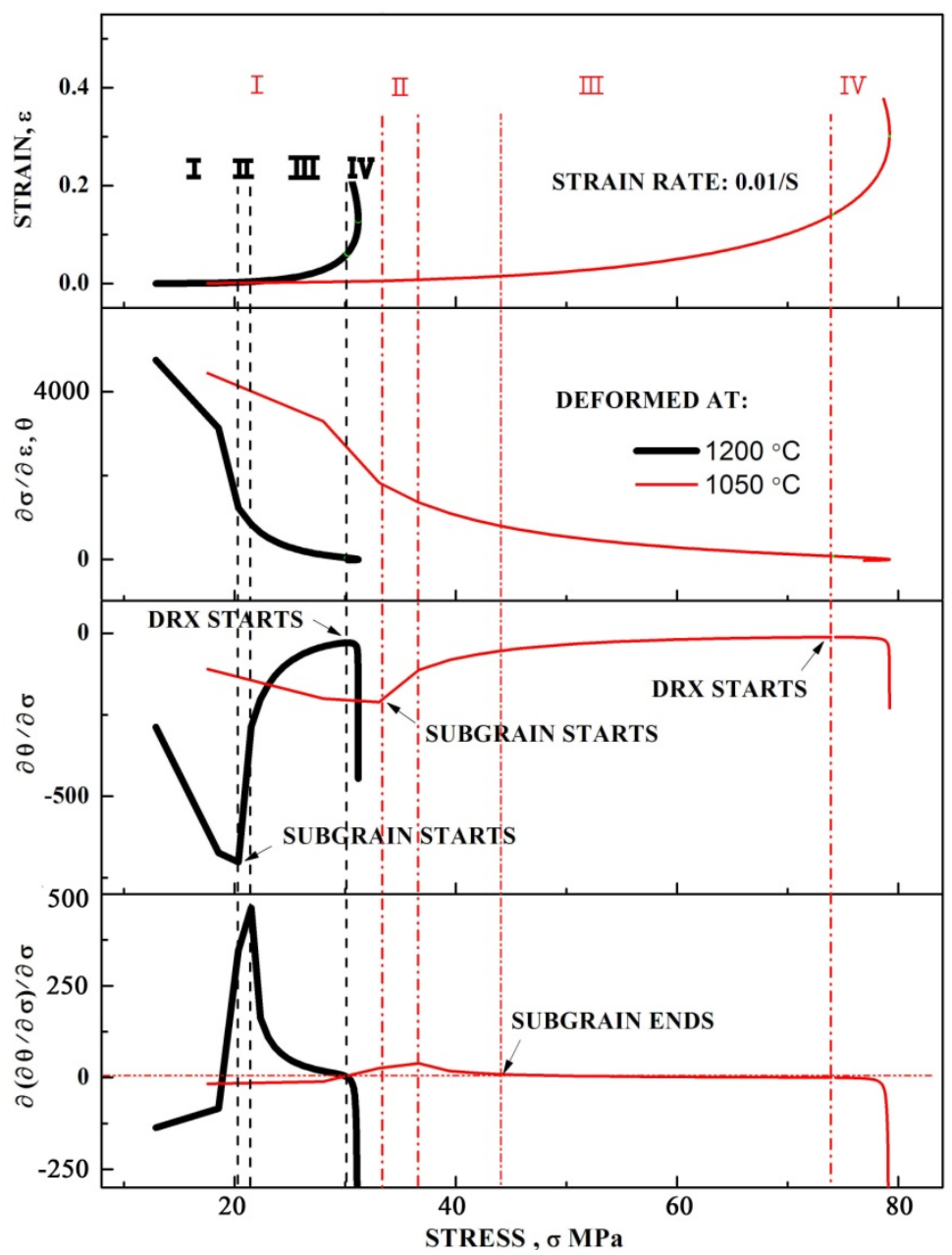

Figure 11. Strain $\varepsilon, \theta, d(d \theta / d \sigma) f \partial \sigma$ versus stress under the deformation condition of $1200^{\circ} \mathrm{C} / 10^{-2} \mathrm{~s}^{-1}$ and $1050{ }^{\circ} \mathrm{C} / 10^{-2} \mathrm{~s}^{-1}$.

\subsection{Microstructure evolution during hot deformation}

The coexistence of multiple competitive softening mechanisms, such as DRV, DSIT, DRX, MDRX, in the NS steel leads to various microstructure characteristics. As discussed above, the DRX has a complementary relationship with DRV during deformation. If DRV consumes most of the stored energy, there would be no sufficient energy in terms of dislocations left for the nucleation of DRX. For instance, the BCC metals, which possess a high stacking fault energy (SFE), lose most of their stored energy through DRV. Thus, DRX in BCC metals is hard to happen. However, DRX occurs in the NS steel under a wide range of deformation conditions even though both DRV and DSIT take place before DRX, confirmed by the analysis of the stress curve 
in Section 4.1. DRV and DSIT together make the DRX hard to happen but on the other hand, they provide a good opportunity for MDRX to occur. However, the effect of DRV and DSIT on DRX and MDRX varies under different deformation conditions.

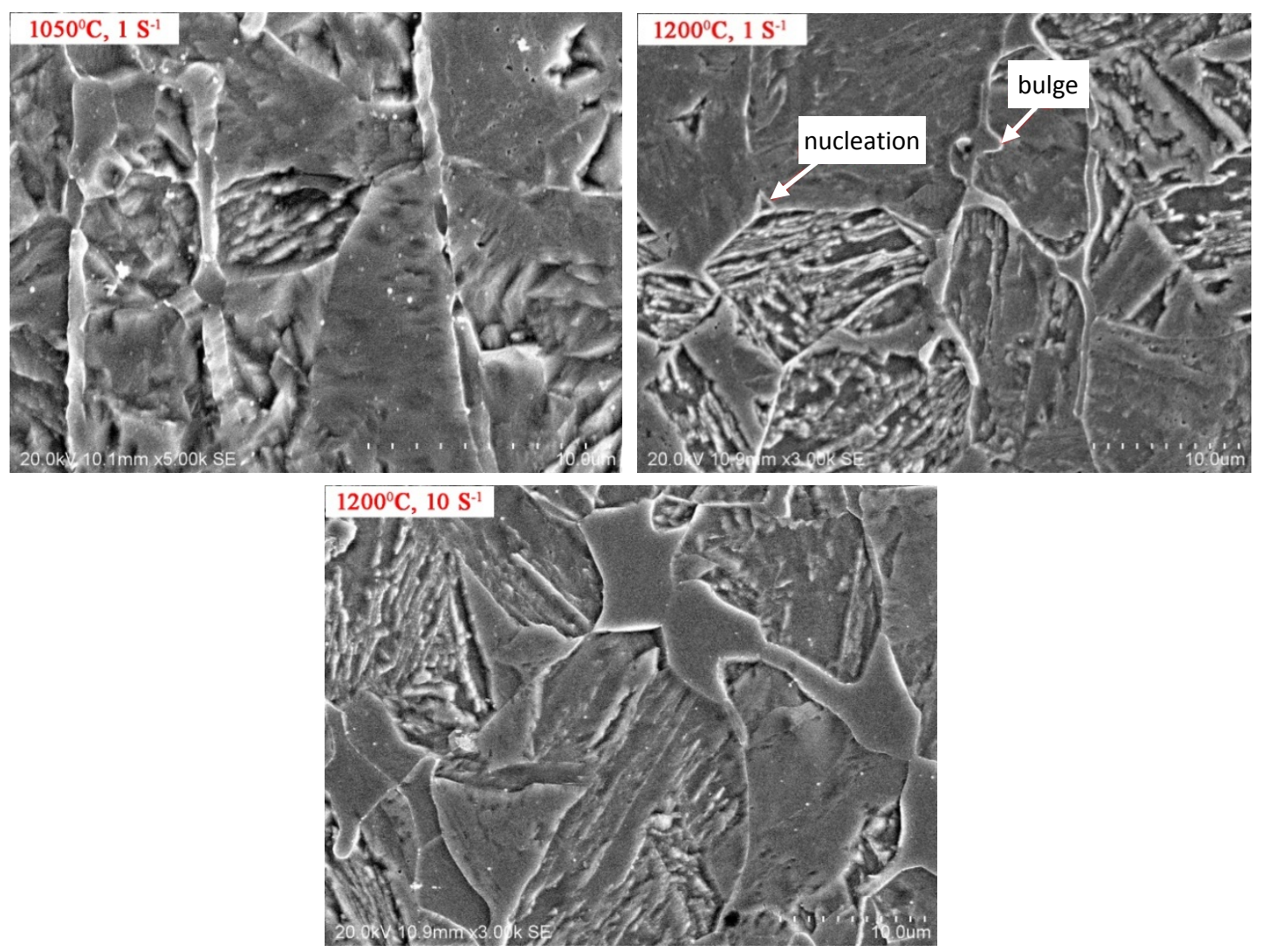

Figure 12. DSIT formation in the NS steel under different conditions as labeled.

Under low $\mathrm{Z}$ condition, such as deforming at $1200^{\circ} \mathrm{C}$, the $\mathrm{DRX}$ grains initiate quickly by growing fluctuations of prior austenite grain boundaries. Serration and bulge develop once the local dislocation density is high enough to allow the new grains to nucleate and grow during the deformation ${ }^{[6]}$. However, DSIT ferrite grains nucleate on the prior austenite boundaries due to large amount of lattice defects such as dislocation, vacancy, interstitial atom and stacking fault. These lattice defects accelerate the DSIT process by augmenting a large scale of ferrite nucleation site distribution. Some authors ${ }^{[14,15]}$ have found that the DSIT takes place in HSLA steel, $\mathrm{C}-\mathrm{Mn}-\mathrm{V}$ steel and $304 \mathrm{~L}^{[16]}$ stainless steel at a critical strain which was markedly reduced with refinement of the prior austenite grain size. Apparently, in the NS steel, 
DSIT initiates and indulges the same way as in those steels, which could be confirmed by Figure 12.
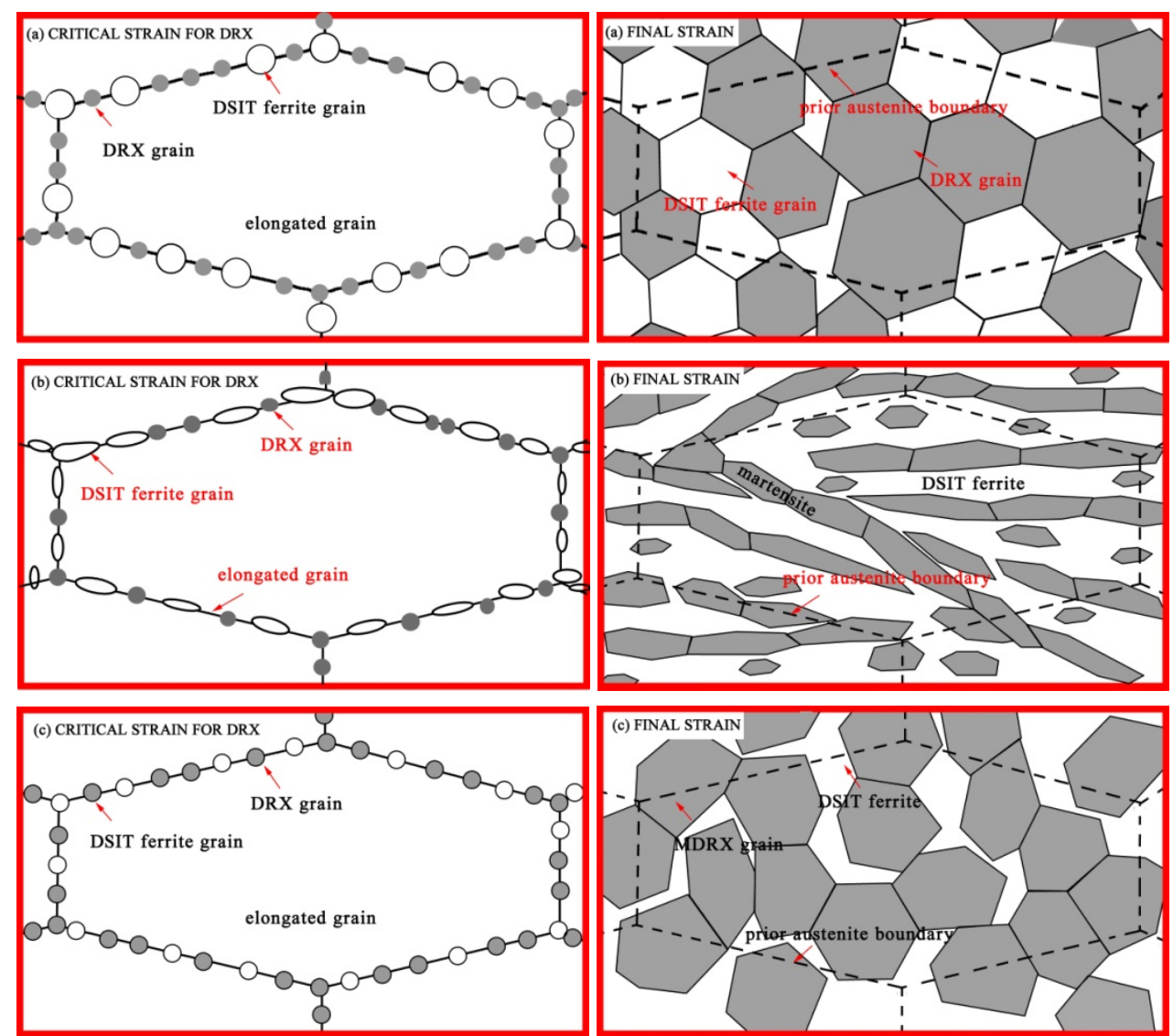

Figure 13. Sketch of microstructure evolution under different deformation conditions. (a) DRX and DSIT at $1200{ }^{\circ} \mathrm{C} / 10^{-3} \mathrm{~s}^{-1}$; (b) DRV and DSIT at $1050{ }^{\circ} \mathrm{C} / 10^{-1} \mathrm{~s}^{-1}$; (c) DRV and DRX at $900{ }^{\circ} \mathrm{C} / 10^{0} \mathrm{~s}^{-1}$.

Since the DSIT occurs before DRX in the NS steel, as discussed in Section 4.1, the DSIT ferrite grains already swell into a sphere shape when the critical strain for DRX initiation is reached at low $\mathrm{Z}$ value, as shown in Figure 13 (a). With the strain increasing, the nucleated grains grow, new DSIT ferrite grains and DRX grains continuously nucleate along the newly formed grain boundaries and inside the grains. When the strain approaches the final value $(\varepsilon=1.2)$, the DRX grains grow into equiaxed shape and the DSIT ferrite grains are polygonal. 
The equiaxed microstructure could be formed only at low $\mathrm{Z}$ value, because the low $\mathrm{Z}$ condition satisfies the necessary prerequisites for the formation, such as high nucleation rate of DRX, and high growth rate of both DRX and DSIT ferrite grains. Meanwhile, at low $\mathrm{Z}$ value, the fine and medium size particles that reduce recovery, stabilize substructure to slow the DRX nucleation, and pin the grain boundaries diminish. Thus, the nucleation of DRX is highly prompted. At high temperature, the nucleation of DSIT is supposed to be retarded thanks to the increase of $\mathrm{Nb}, \mathrm{C}, \mathrm{V}$ and $\mathrm{N}$ solute atom amount, especially $\mathrm{Nb}$ solute content which segregates on austenite boundaries and lowers the boundary energy, thus leading to a dramatic reduction in nucleation rate of DSIT ferrite ${ }^{[17]}$. However, in the case of NS steel deformation, since the nucleation rates of DSIT ferrite are all very low under various deformation conditions and thus have very little contribution to the fraction of ferrite, the growth of DSIT ferrite becomes the main factor that affects the volume fraction of the ferrite in the microstructure. At the temperature of $1200{ }^{\circ} \mathrm{C}$, the formed ferrite has a free energy high enough for it to grow even perpendicular to the austenite grain boundaries.

Thereby, the martensitic grains show small, equiaxed grains due to DRX whilst the DSIT ferrite demonstrates the polygonal grains along with few DRX ferrite grains, indicated by arrows in Figure 9(a), owing to the high temperature. Generally speaking, ferrite could hardly experience DRX since it is a BCC metal possessing a higher SFE than the FCC metal ${ }^{[18]}$. In steels with low SFE, there is separation between partial dislocations and, therefore, cross slip and climb are very difficult. This means that the grain rotation will be adversely affected due to the lack of dislocation motion across obstacles $^{[14]}$. In this case, the disorientation is rapidly accelerated to the critical amount for the occurrence of DRX. Thereby, the DSIT ferrite could hardly experience DRX owing to its high SFE.

Since DSIT starts prior to DRX, the DSIT ferrite grains have already inflated into an eggplant shape along the prior austenite grain boundaries when the critical strain for 
DRX initiation is reached. Therefore, when the strain reaches 1.2 , the microstructure evolves into a dual phase structure comprised by equiaxed DRX austenite grains and stripe DSIT ferrite grains as demonstrated in Figure 13(b) and Figure 9(b) under low $\mathrm{Z}$ value situation, especially at $1050{ }^{\circ} \mathrm{C} / 10^{-1} \mathrm{~s}^{-1}$. This typical microstructure is mainly caused by different growth rates of the DSIT ferrite grains and the DRX grains in the NS steel, because the temperature under such condition is high enough for the DSIT ferrite grains to grow and sufficient for the DRX grains to nucleate but not high enough for them to grow. As mentioned above, under all deformation conditions, the nucleation rate of the DSIT ferrite is small in the NS steel. Thus, the growth of DSIT ferrite determines the volume fraction of ferrite which is the main softening mechanism under this condition. Unlike HSLA steel, the NS steel contains only 0.02 wt.\% $\mathrm{C}$ which is one of the most significant elements to expand the ferrite phase zone $^{[19]}$. A large part of it is strain-induced during the deformation, as shown in Figure 12, which gives a good chance and an advanced reason for the initiation of DSIT ferrite. However, at the same time, there is also $9 \mathrm{wt} . \% \mathrm{Cr}$ in the NS steel that is in the solute state during the whole deformation process, which would strongly inhibit the amount of ferrite nuclei, as $\mathrm{Cr}$ is also one of the most powerful strengthening elements in ferrite. All the reasons above lead to the microstructure with small elongated DRX martensite and wide stripe DSIT ferrite at $1050{ }^{\circ} \mathrm{C}$, as sketched in Figure 13(b) and Figure 9(b).

However, the NS steel displays finer martensite DRX grains at the deformation condition of $900{ }^{\circ} \mathrm{C} / 10^{0} \mathrm{~s}^{-1}$ than at $1200{ }^{\circ} \mathrm{C} / 10^{-3} \mathrm{~s}^{-1}$. As explicitly explained above, the DRX occurs at a lower strain when the steel is deformed at a relatively high temperature. Under this theory, there would be relatively smaller grains formed at the $1200{ }^{\circ} \mathrm{C} / 10^{-3} \mathrm{~s}^{-1}$ condition. However, the microstructure showed the opposite. To explain the phenomenon, the following aspects of theories would be taken into account: the multiple peaks in stress curve, the MDRX behavior, the strain rate, and the strain-induced precipitation. When the multiple peaks occur, the grains coarsen as the average initial grain size, which the average DRX grain size strongly depends on, 
decreases after each peak. The stress curve distinctly shows multiple peaks under the $1200{ }^{\circ} \mathrm{C} / 10^{-3} \mathrm{~s}^{-1}$ condition, which would result in coarse grains. The MDRX governs the subsequent post-dynamic softening once the strain reaches the critical value which is larger than $\varepsilon_{\mathrm{c}}$ for DRX and smaller than the steady state $\operatorname{strain}^{[3]}$. Thus, as the steady strain at $900{ }^{\circ} \mathrm{C}$ is much smaller than that at $1200{ }^{\circ} \mathrm{C}$, the MDRX initializes at a relatively small strain at $900{ }^{\circ} \mathrm{C}$ and refines the grains more effectively. Furthermore, the MDRX kinetics primarily depends on strain rate with a small effect of temperature. In other words, the MDRX grain size depends only on the $\mathrm{Z}$ parameter $^{[20]}$ and is finer with the increase of $Z$ value. Therefore, when deformed at a higher strain rate of $10^{0} \mathrm{~s}^{-1}$, the MDRX is formed in the NS steel more efficiently than at $10^{-3} \mathrm{~s}^{-1}$.

Therefore, under the theory mentioned above, the model of microstructure evolution under the condition of $900{ }^{\circ} \mathrm{C}$ is depicted in Figure 13(c). Unlike the other two conditions, the temperature in this condition greatly limits the growth of both DSIT ferrite and DRX grains. Thereby, the DSIT ferrite grains barely change when the critical strain for DRX initiation approaches. With the strain arriving at 1.2, DRX austenite grains and some martensite-ferrite blends are formed without distinct DSIT ferrite grains. However, the deformation condition is suitable for the progress of MDRX which leads to the final near-equiaxed martensitic grains.

Specifically, DRX nucleation is retarded by increasingly fast concurrent straining which introduces additional dislocations into the forming nucleus with the strain rate increasing. Thus, the nucleation requires a greater strain energy gradient across the boundary and a smaller cell size ${ }^{[1]}$. However, increasing strain rate also increases the proportion of strain caused by dislocation climbing which would mount the SFE and accelerate the proceeding of DRX once it occurs. This explains the formation of finer DRX martensite grains at a relatively high strain rate of $900{ }^{\circ} \mathrm{C} / 10^{0} \mathrm{~s}^{-1}$ than at 1200 ${ }^{\circ} \mathrm{C} / 10^{-3} \mathrm{~s}^{-1}$. 
Since samples of the NS steel are all heated to $1200{ }^{\circ} \mathrm{C}$ and then cooled to the deformation temperature with reduction of $60 \%$, as illustrated in Figure 1, effects of the initial grain size and the strain amount on DSIT formation behavior were the same. However, the strain induced precipitates, which are sensitive to both temperature and strain rate, have a positive influence on the DSIT nucleation sites. When deformed at a lower temperature, e.g. $900{ }^{\circ} \mathrm{C}$, which is the nose precipitation temperature for the $\mathrm{NbX}$ compound, large amount of deformation-induced precipitates formed, as shown in Figure 14. Considering the composition and deformation temperature, the precipitates were niobium carbonitrides which were intended in the NS steel. They acted as the ferrite nucleation sites, increased the generation rate of dislocations, made the slip of dislocation difficult, and therefore accelerated the formation of DSIT ferrite. This is why the DSIT ferrite showed finer grains at the deformation temperature of $900{ }^{\circ} \mathrm{C}$ than at $1200{ }^{\circ} \mathrm{C}$, but smaller ferrite fraction owing to the low growth rate. At $1200{ }^{\circ} \mathrm{C}$, the DSIT ferrite inflated easily, resulting in augmentation of ferrite fraction due to the high free energy in ferrite and the absence of carbonitrides that retard the boundary movement.

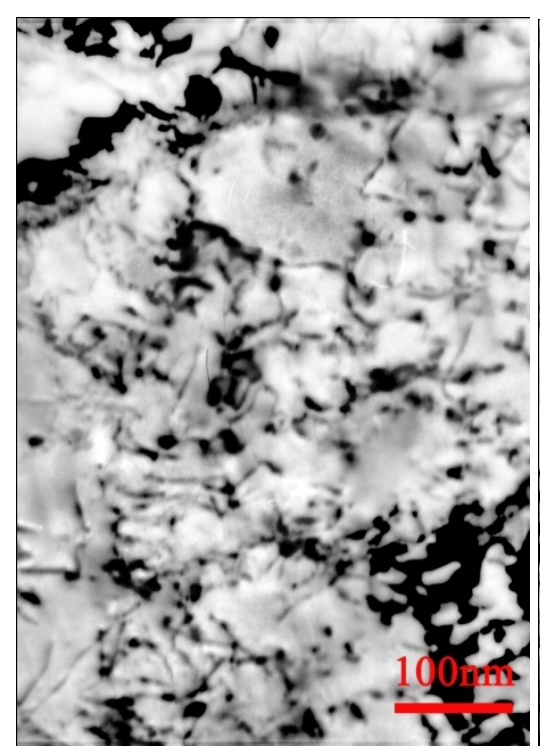

(a)

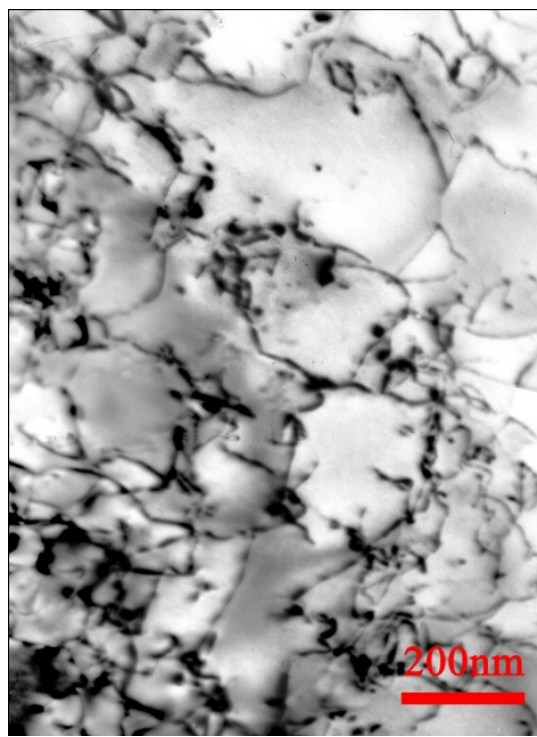

(b)

Figure 14. Deformation-induced formation of precipitates during different conditions:

(a) $900{ }^{\circ} \mathrm{C} / 10^{-3} \mathrm{~s}^{-1}$; (b) $1050{ }^{\circ} \mathrm{C} / 10^{-3} \mathrm{~s}^{-1}$. 


\section{Conclusion}

Beneath the diversity of steel microstructures and hot deformation processes, there are some fundamental characteristics of the NS steel.

(1) The precise strain starting and ending for dynamic recovery (DRV) could be determined by the maximum of $-\partial \theta / \partial \sigma$ and the value closest to zero of $-\partial(\partial \theta / \partial \sigma) / \partial \sigma$, respectively. The critical conditions for DRX, the critical amount of stored energy and the minimum of energy dissipation rate could be precisely located by the minimum of $-\partial \theta / \partial \sigma$.

(2) $\ln \left(\varepsilon_{c}\right)$ increased linearly with $\ln (Z)$ at the beginning but the rate reduced and leveled off at high $\mathrm{Z}$ conditions. $\ln \left(\sigma_{\mathrm{c}}\right)$ curve kept a smaller linear growth trend when $\ln (Z)$ value was beyond 40 .

(3) The stress-strain curves up to the peak could be divided into four regions by the characteristics in $\partial \theta / \partial \sigma$ and $\partial(\partial 0 / \partial \sigma) / \partial \sigma$ curves. Each region corresponded to different processes, namely deformation hardening, DRV softening, DSIT softening and DRX softening, in this sequence.

(4) DRX has a complementary relationship with DRV. The high strain rate accelerates the proceeding of DRX once the DRX occurs, while a high temperature provokes the start of DRX at lower strain and prompts its proceeding as well. MDRX aids the grain refinement along with DRX.

(5) The allotriomorphic DSIT grains were initiated and grew along the prior austenite grain boundaries under all $\mathrm{Z}$ conditions. No DRX occurred in the DSIT ferrite, whilst it happened in the martensitic grains, leading to small grain size. The growth rate of DSIT ferrite was positively sensitive to the temperature. 


\section{Acknowledgements}

This work was financially supported by National Basic Research Program of China (No. 2010CB630800) and National Natural Science Foundation of China (No. $51001102)$.

\section{References}

[1] McQueen, H.J., Ryan, N. D., Mater. Sci. Eng. A 322 (2002) 43-63.

[2] Marchattiwar, A., Sarkar, A., Chakravartty, J. K., Kashyap, B. P., J. Mater. Eng. Perform. 22 (2013) 2168-2175.

[3] Fernández, A. I., Uranga, P., López, B., Rodriguez-Ibabe, J. M., Mater. Sci. Eng. A 361 (2003) 367-376.

[4] McQueen, H. J.,Yue, S., Ryan, N. D., Fry, E., J. Mater. Process. Technol. 53 (1995) 293-310.

[5] Zhang, W., Yan, W., Sha, W. et al., Sci. China Technol. Sci. 55 (2012) 1858-1862.

[6] Taylor, A. S., Hodgson, P. D., Mater. Sci. Eng. A 528 (2011) 3310-3320.

[7] Zhang, W. F., Li, X. L., Yan, W., Shan, Y. Y., Yang, K., in 5th Symposium on Heat Resistant Steels and Alloys for High Efficiency USC/A-USC Power Plants (2013), Seoul, Korea Institute of Science and Technology.

[8] Wray, P. J., Metall. Trans. A 6 (1975) 1197-1199.

[9] Poliakt E. I., Jonas, J. J., Acta Mater. 44 (1996) 127-136.

[10] Sandstrom, R., Lagneborg, R., Scripta Metall. 9 (1975) 59-99.

[11] Stewart, G. R., Jonas, J. J., Montheillet, F., ISIJ Int. 44 (2004) 1581-1589.

[12]Roberts, W., Ahlblom, B., Acta Metall. 26 (1978) 801-813.

[13] Sandstrom, R., Lagneborg., R. Acta Metall. 23 (1975) 387-398.

[14]Beladi, H., Kelly, G. L., Shokouhi, A., Hodgson, P. D., Mater. Sci. Eng. A 371 (2004) 343-352.

[15]Dong, H., Sun, X., Curr. Opin. Solid St. M. 9 (2005) 269-276. 
[16]Hong, S. C., Lee, K. S., Mater. Sci. Eng. A 323 (2002) 148-159.

[17]Hong, S. C., Lim, S. H., Hong, H. S. et al., Mater. Sci. Eng. A 355 (2003) 241248.

[18]Poirier, J. P., Plasticité à haute température des solides cristallins, editions eyrolles (1976).

[19]Zhang, W. F., Hu, P., Yan, W. et al., J. Iron Steel Res. Int. supplement 1-1 18 (2011) 143-147.

[20]Uranga, P., Fernández, A. I., López, B., Rodriguez-Ibabe, J. M., Mater. Sci. Eng. A 345 (2003) 319-327. 


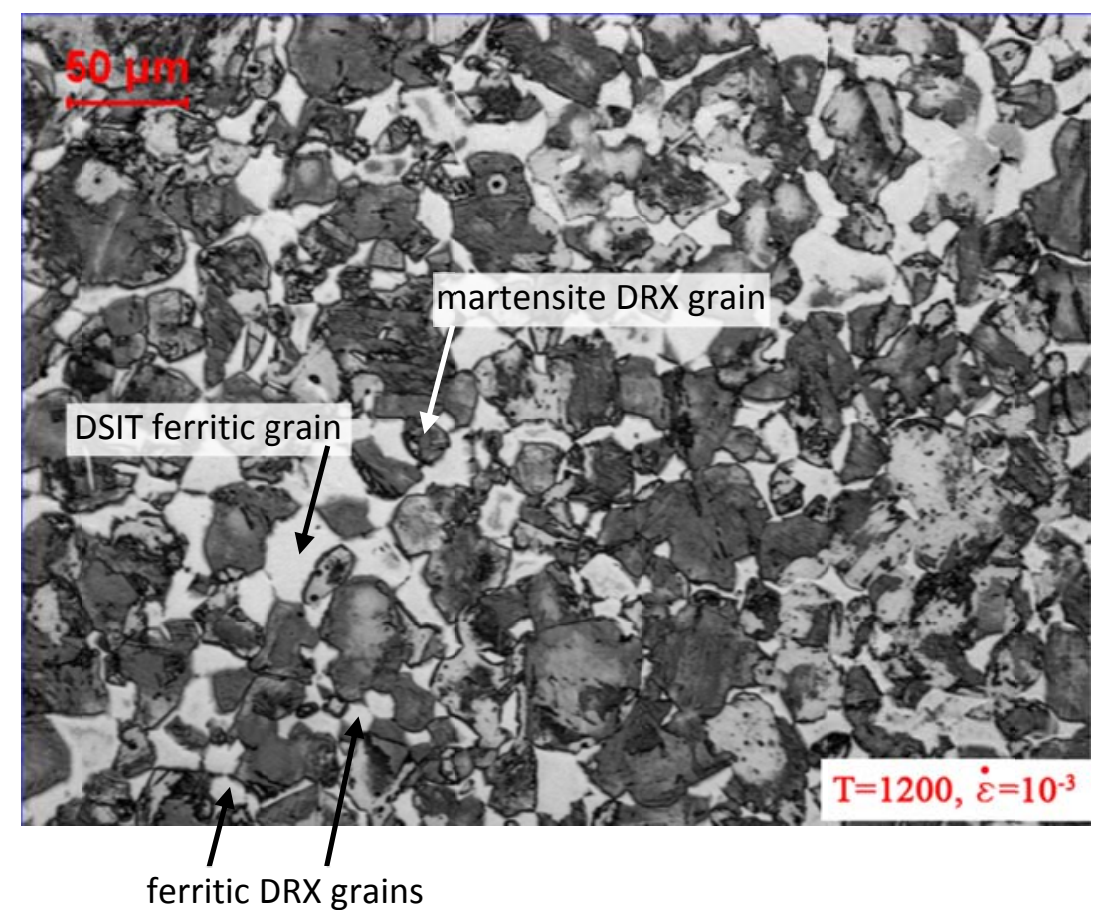

Fig. 9a

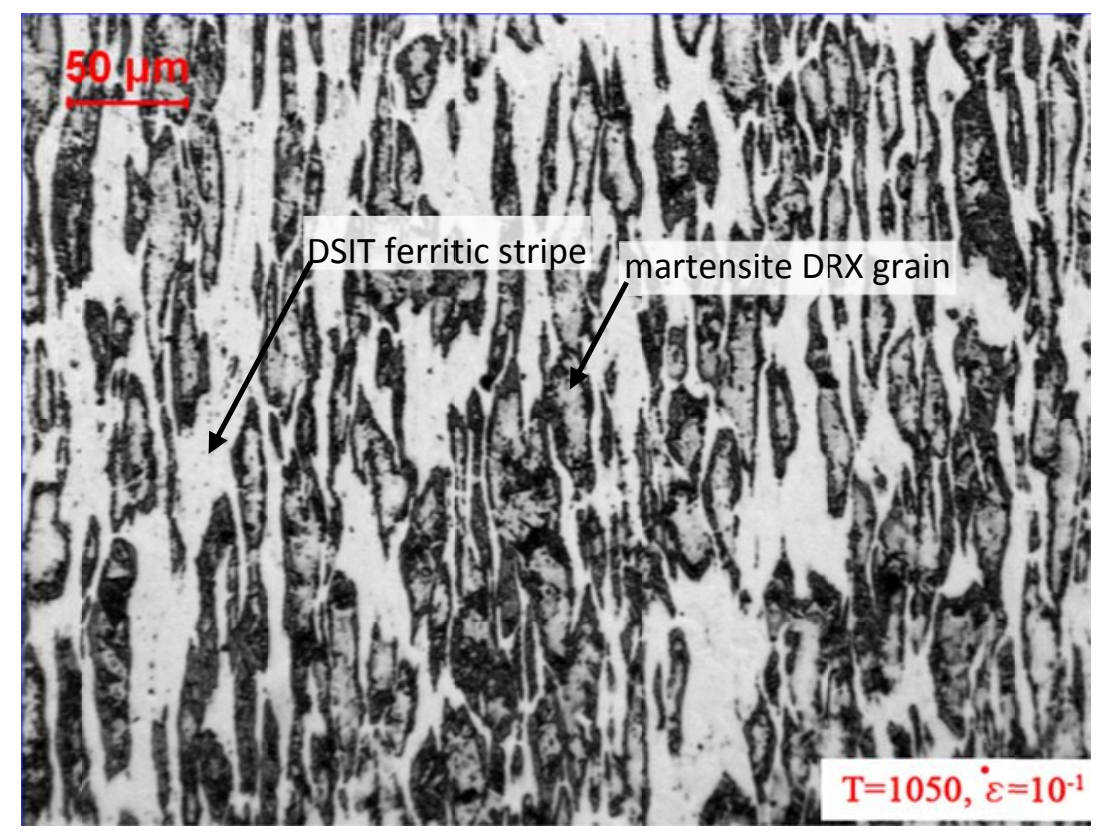

Fig. 9b 


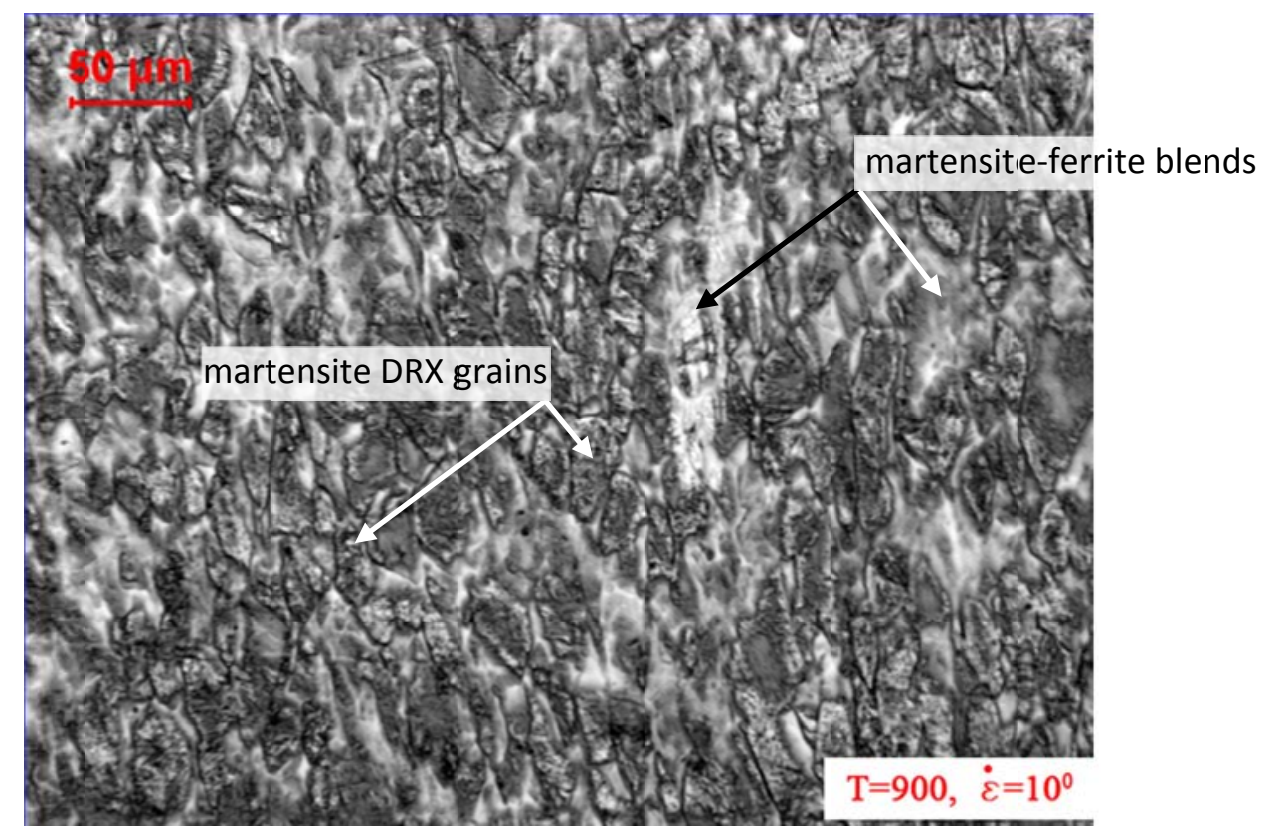

Fig. 9c 